\title{
Bone Mineral Density is Associated with Hypercalciuria in Primary Hyperparathyroidism
}

${ }^{1}$ Department of Internal Medicine, Section of Endocrinology and Metabolism, Marmara University Hospital, Marmara University School of Medicine, İstanbul, Turkey

${ }^{2}$ Department of Internal Medicine, Marmara University Hospital, Marmara University School of Medicine, İstanbul, Turkey

Aim: The most common clinical presentation of primary hyperparathyroidism (PHPT) is asymptomatıc and it is diagnosed incidentally without developing complications .In our study, we aimed to examine the characteristics of participants with primary hyperparathyroidism and the relationship between bone mineral density (BMD) and hypercalciuria.

Methods: Consecutive 191 normocalciuric (24-hour urinary calcium<400 mg/day) patients with PHPT (51 \pm 13 years, F/M:155/36), 61 hypercalciuric (24-hour urinary calcium $>400 \mathrm{mg} /$ day) patıents with PHPT $(49,2 \pm 10$ years, F/M:50/11) and 55 healthy controls (38,8 \pm 10 , F/M:43/12) were included in the current study. Serum calcium, phosphorus, parathyroid hormone (PTH), 25(OH) vitamin D and 24-hour urinary calcium were measured in all three groups. DEXA method was used for BMD measurement.
Results: Serum calcium levels were 11,8 $\pm 0,9 \mathrm{mg} / \mathrm{dl}$, $10,6 \pm 1,3 \mathrm{mg} / \mathrm{dl}$ and 9,6 $\pm 0,3 \mathrm{mg} / \mathrm{dl}$ ( $p<0.0001)$, serum parathyroid hormone levels were $287 \pm 378,2 \mathrm{pg} / \mathrm{ml}$, $212 \pm 322 \mathrm{pg} / \mathrm{ml}$ and $61,3 \pm 28 \mathrm{pg} / \mathrm{ml}(\mathrm{p}<0.001)$ for hypercalciuric, normocalciuric patients and control group respectively. 24-hour urinary calcium levels were 600 \pm 173 $\mathrm{mg} /$ day in hypercalciuric group, $196 \pm 106 \mathrm{mg} /$ day in normocalciuric group and $137 \pm 69$ in healthy controls group $(p<0,0001)$. Serum calcium levels were observed significantly higher and serum phosphorus levels were observed significantly lower in hypercalciuric group compared to normocalciuric group and healthy control group $(p<0.0001, p=0.005)$. Serum PTH levels were observed significantly higher in hypercalciuric group compared to normocalciuric $\operatorname{group}(p=0,03)$. 24-hour urinary calcium levels showed positive correlation with PTH and serum calcium levels $(r=-0.37, r=0.47, p<0,0001)$ and negative correlation with femur neck and lomber BMD levels in PHPT patients. $(r=-0,23, p=0,001 ; r=-0,27, p=0,02)$. Patients whose serum calcium levels were normal or mildly elevated were tested for CGR mutation and it resulted negative.

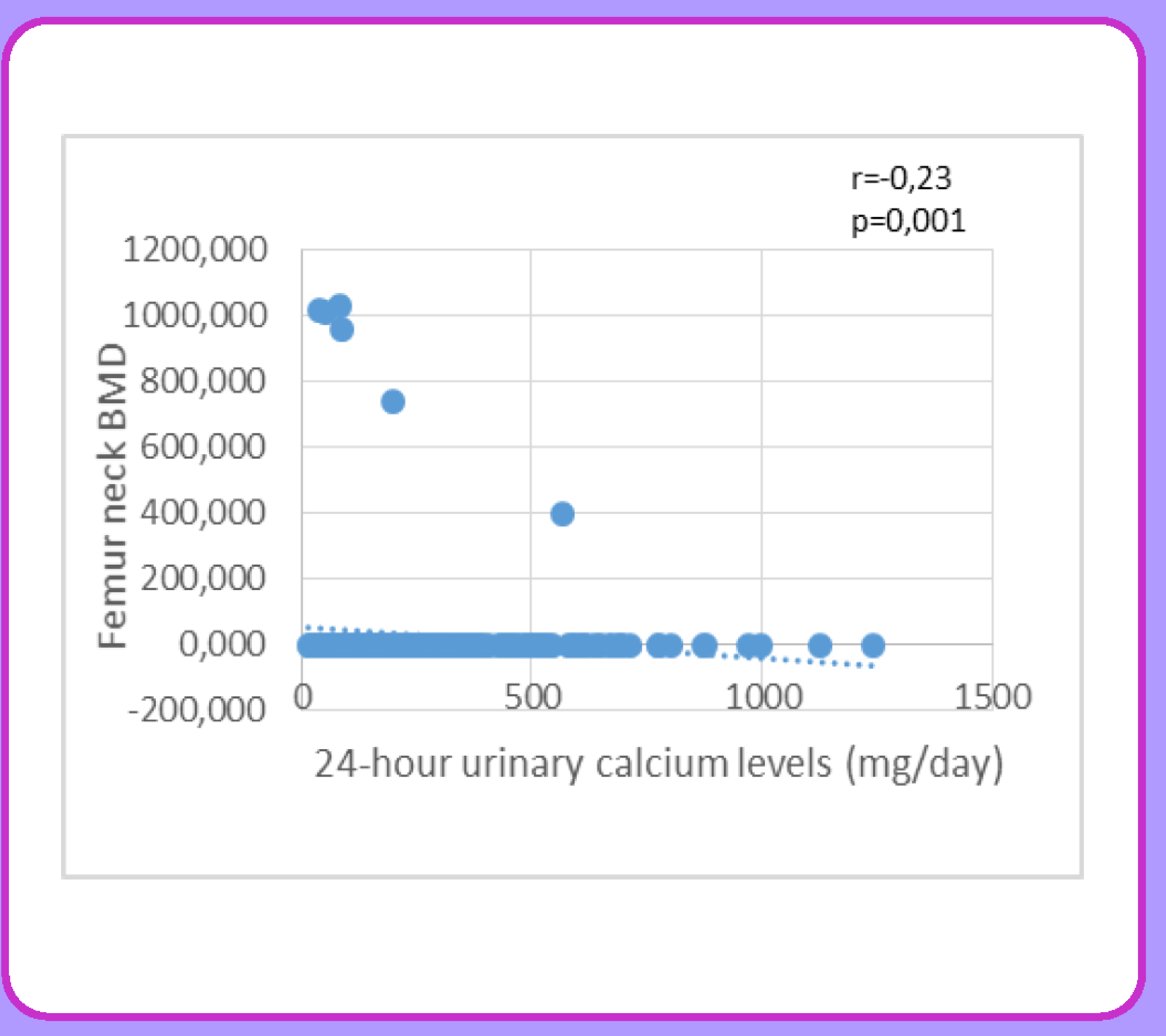

\begin{tabular}{|c|c|c|c|c|}
\hline & $\begin{array}{c}24 \text { Hour Urinary } \\
\text { Calcium }<400 \mathrm{mg} / \text { day } \\
\text { n:191 }\end{array}$ & $\begin{array}{c}24 \text { Hour Urinary } \\
\text { Calcium }>400 \mathrm{mg} / \text { day } \\
\text { n:61 }\end{array}$ & $\begin{array}{c}\text { Control } \\
\text { Group } \\
\text { n:55 }\end{array}$ & $p$ \\
\hline Calcium (mg/dl) & $10,6 \pm 1,3$ & $11,8 \pm 0,9$ & $9,6 \pm 0,3$ & $<0,0001$ \\
\hline Phosphours (mg/dl) & $2,6 \pm 0,5$ & $2,4 \pm 0,5$ & $3,2 \pm 0,4$ & $<0,0001$ \\
\hline $\begin{array}{l}\text { Parathyroid Hormone } \\
(\mathrm{pg} / \mathrm{ml})\end{array}$ & $212 \pm 322$ & $287 \pm 378$ & $61,3 \pm 28$ & $<0,0001$ \\
\hline $25(\mathrm{OH}) \mathrm{D}(\mathrm{ng} / \mathrm{mll})$ & $22,1 \pm 15,9$ & $23,1 \pm 32,3$ & $12,1 \pm 10,4$ & $<0,0001$ \\
\hline $\begin{array}{l}24 \text { Hours Urinary } \\
\text { Calcium (mg/day) }\end{array}$ & $196 \pm 106$ & $600 \pm 173$ & $137 \pm 69$ & $<0,0001$ \\
\hline
\end{tabular}

Conclusion: Our study also showed that there is positive correlation between urinary calcium levels and serum PTH levels in newly diagnosed PHPT patients. It also supports the opinion that hypercalciuria could be a marker bone loss in PHPT patients. 